\title{
Bioética e processos de religiosidade entre os pacientes com doenças terminais no Brasil
}

\section{Resumo}

Os avanços tecnocientíficos das últimas décadas contribuíram para o aumento do número de pacientes com doenças terminais no mundo. Em decorrência da milenar conexão entre a fase de terminalidade de vida e os processos espiritualistas, esse fato assumiu aspectos peculiares no Brasil, país em que o número de segmentos religiosos/espiritualistas multiplicou-se nas últimas décadas. Este trabalho procura mostrar que a diversificação das necessidades de pacientes brasileiros com referência ao bem-estar espiritual na fase final da vida pode gerar dilemas bioéticos novos para o profissional da saúde que não conheça os fundamentos das principais correntes espiritualistas do país. Defendendo que tal conhecimento é ferramenta útil para o profissional da saúde que quer observar os princípios da beneficência e do respeito à autonomia do paciente, o texto disponibiliza algumas orientações básicas das principais linhas espiritualistas brasileiras sobre os processos da morte e do morrer.

Palavras-chave: Bioética. Autonomia. Testamento vital. Terminalidade de vida. Crenças religiosas. Paciente terminal. Doença terminal.

\section{Resumen}

Bioética y procesos de religiosidad entre los pacientes con enfermedades terminales en Brasil

Los avances tecnocientíficos de las últimas décadas contribuyeron para aumentar la cantidad de pacientes con enfermedades terminales en el mundo. Por consecuencia de la milenaria conexión entre la fase de terminación de la vida y los procesos espiritualistas, este hecho adquirió aspectos peculiares en Brasil, país en que el número de segmentos religiosos/espiritualistas se multiplicó los últimos años. El presente trabajo busca mostrar que la diversificación de las necesidades de pacientes brasileños en relación al bienestar espiritual en la fase final de la vida puede generar nuevos dilemas bioéticos al profesional de salud que ignore los fundamentos de las principales corrientes espiritualistas del país. Defendiendo que este conocimiento se constituya en herramienta útil para el profesional de sanidad que desee observar los principios de beneficencia y respeto a la autonomía del paciente, el texto dispone las orientaciones básicas de las principales líneas espiritualistas brasileñas sobre los procesos de muerte y de morir.

Palabras-clave: Bioética. Autonomía. Testamento vital. Terminación de la vida. Creencias religiosas. Paciente terminal. Enfermedad terminal.

\begin{abstract}
Bioethics and religious processes among terminally ill patients in Brazil

The techno scientific advances in the last decades have contributed to increase the number of terminally ill patients in the world. Given the millenary connection between life's terminal phase and spiritualist processes, this fact has gained peculiar shades in Brazil, a country where the number of religious/spiritualist-oriented segments has also multiplied in the last decades. This study seeks to demonstrate that the diversification of Brazilian terminally ill patients' needs regarding the spiritual wellbeing may bring about new bioethical dilemmas for health professionals who are not familiar with the tenets of the current main spiritualist followings in Brazil. Supporting the fact that this knowledge is an important tool for health professionals who seek to observe the principles of beneficence and patient's autonomy, this paper provides some basic orientations of the main Brazilian spiritualist tenets about the processes of death and dying.

Keywords: Bioethics. Autonomy. Living will. Life terminality. Religious beliefs. Terminal patient. Terminal illness.
\end{abstract}

Mestre alvaroangelo7@yahoo.com - Escola de Medicina da Faculdade de Minas (Faminas), Belo Horizonte/MG, Brasil.

Correspondência

Rua Euclásio 231, apto. 504. Santa Efigênia CEP 30260-210. Belo Horizonte/MG, Brasil.

Declara não haver conflito de interesse. 
Dois fatos, aliados, contribuiriam para o surgimento recente de algumas situações dilemáticas para o profissional da saúde no Brasil: os avanços tecnológicos e científicos que levaram ao aumento da vida média da população do mundo e, naturalmente, do número de pacientes em fase terminal; e a multiplicação das religiões, das seitas e dos segmentos de cunho espiritualista no Brasil, em paralelo à perda da hegemonia da Igreja Católica no país. Dada a milenar conexão entre a fase terminal da vida e os processos espiritualistas, começou a crescer o número de solicitações de pacientes com referência a posturas ou ritos com os quais o profissional da saúde brasileiro talvez não estivesse familiarizado, o que gerou dilemas.

Os princípios da bioética são aqui apresentados como um caminho para auxiliar na solução do impasse, dando-se ênfase aos princípios do respeito à autonomia, da beneficência e da alteridade. Como suporte para a prática de tais princípios, são apresentadas e discutidas informações básicas sobre a morte e o morrer da perspectiva de algumas das principais religiões, seitas ou correntes espiritualistas existentes atualmente no Brasil.

\section{A tecnologia e a questão da morte}

Graças aos profundos avanços tecnológicos e científicos ocorridos a partir do início do século XX, tornou-se possível prolongar a vida humana por períodos nunca imaginados. Segundo projeções de Camarano ${ }^{1}$, o número de idosos no mundo em 2050 corresponderá a quase um quarto da população. No Brasil, em 1950, o percentual de pessoas com mais de 60 anos era de 4,9\%; em 2000, de $7,8 \%$; a projeção para 2050 é de $23,6 \%$. Ao mesmo tempo, os limites do período conhecido como terminalidade de vida têm sido diretamente afetados pelas possibilidades médico-tecnológicas de se manter um paciente vivo por períodos prolongados.

Nunes ${ }^{2}$ considera como doente terminal aquela pessoa que está na fase final da vida, sendo sempre casuística a determinação desse período. Acredita ainda o autor que, em uma acepção generalizada, esse termo aplique-se ao paciente cuja doença não responde a nenhuma terapêutica conhecida, encontrando-se ele num processo que conduz irreversivelmente à morte. A essas características acrescentamos as observações da Associação Portuguesa de Cuidados Paliativos (APCP) ${ }^{3}$, que entende como doente terminal a pessoa que tem, em média, de três a seis meses de vida, período estimado por critérios de objetivação de prognóstico. Como o paciente pode estar incapacitado de expressar seus pensamentos, fica subentendido, para efeitos desta discussão, que suas vontades poderão ser expressas por seu representante legal ou sua família.

No século XX, a medicina foi profundamente afetada pelo cientificismo e por um acelerado processo de tecnicização. Esses fatores fizeram que questões mais abstratas e sutis se desconectassem gradualmente da prática médica. Como o fator humano não mais acompanhou pari passu a evolução técnica, o hospital passou a correr sério risco de não ser mais fiel a sua primordial função, isto é, a hospitalidade. Conforme Salles ${ }^{4}$, o desafio tornou-se optar entre tecnologia e calor humano, ou então integrar ao desenvolvimento tecnológico um caráter humanístico. Esta última opção foi defendida por Potter ${ }^{5}$, que enfatizou a necessidade de reunir conhecimento biológico com valores humanos para se alcançar uma nova sabedoria atinente aos dias atuais. No início da década de 1970, Hellegers ${ }^{6}$ previa que os problemas que se apresentariam aos médicos nas décadas subsequentes seriam cada vez mais de natureza ética e cada vez menos de natureza técnico-biológica.

No cerne dessa discussão, os dilemas éticos em torno do tema da morte evidentemente seriam de relevância e grande complexidade. Afinal, o tabu da morte (pois assim é geralmente considerada) revela-se, em sua essência, como o da intimidade. Se começarmos a olhar para o fenômeno, veremos que, ao tratar dele, é para a profundidade de nós mesmos que estaremos dirigindo o olhar. "Quem sou? De onde vim? Para onde vou? Existe um além? Tenho autonomia sobre os procedimentos a serem feitos em meu corpo? E sobre a decisão do momento da minha morte?" Fazer esse enfrentamento nos obriga a uma reflexão sobre nossa própria vida, nosso fundamento enquanto seres humanos, nossos valores mais profundos. No mundo atual, tais questionamentos são geralmente evitados, mas, no caso dos profissionais da saúde que lidam com doenças terminais, não há como fugir do âmbito de tais reflexões.

Dilemas de natureza espiritual na terminalidade de vida

Durante o decurso do adoecer, o paciente já conhece um processo de perdas, dores e ansiedade. Ele enfrenta rupturas sociais e torna-se vulnerável ao ser retirado de seu ambiente sociofamiliar, tendo então de procurar um sentido de vida condizente 
com essas novas condições. Com a perspectiva da morte, aumenta a complexidade desses processos e, consequentemente, aumentam as questões éticas e existenciais sobre se, quando e em que grau o profissional da saúde deve intervir. Surge a necessidade de estabelecer critérios claros e precisos para uma boa prática clínica por parte dos profissionais envolvidos.

$\mathrm{Na}$ busca desses critérios, percebe-se com facilidade que, ultimamente, fortaleceu-se o entrelaçamento entre medicina, bioética e psicologia, já que o homem pode ser considerado, em primeira instância, um ser biopsicossocial, havendo muitas facetas a serem consideradas em seus cuidados. Barnard e colegas ${ }^{7}$ defenderam a necessidade de os profissionais terem também conhecimentos sociológicos e culturais do processo da morte, além de habilidades de comunicação e da prática do autoconhecimento e da reflexão. Entretanto, é a faceta da espiritualidade que, quase inevitavelmente, se manifesta de modo significativo no período de terminalidade de vida.

Quase sempre há um tipo de manifestação religiosa presente nos ritos da morte e do morrer, por mais que a pessoa envolvida tenha adotado no decorrer da vida uma posição contrária a quaisquer religiões ou crenças. Inevitavelmente há um parente, amigo ou alguém interessado na tranquilidade do doente ou do falecido em nível diferente do físico. E esta pessoa lhe traz objetos que supostamente curam ou causam bem-estar, ou dedica ao morto uma oração durante o funeral, ou estende seu consolo aos familiares com frases ditadas por fundamentos de espiritualidade. $O$ doente, por sua vez, encontra-se em situação de vulnerabilidade, e, assim, sua busca por apoio ou socorro pode aumentar seu desejo de que, na ocasião, sejam adotados certos procedimentos ligados a sua área espiritual. Contudo, as peculiaridades dos desejos de cunho espiritualista do doente podem significar procedimentos distintos dos padronizados em hospitais.

Quando isso se passa em um país multicultural como o Brasil, onde várias raças se mesclam e convivem inúmeros tipos de imigrantes, a questão é mais complexa, pois maior é o número de religiões, seitas ou doutrinas seguidas. Durante séculos, a Igreja Católica ditou para os brasileiros os rituais ligados à morte. Pelo censo de 1872, 99,6\% dos brasileiros eram católicos. Já nas três últimas décadas a porcentagem foi de $64 \%$. E observa-se contínua tendência de queda, com diminuição de $12 \%$ do índice só na última década, conforme o Instituto Brasileiro de Geografia e Estatística (IBGE) ${ }^{8}$. Ao mesmo tempo, testemunha-se uma multiplicação de segmentos religiosos no país, que adotam diferentes pensamentos sobre a morte e o morrer.

Não é difícil constatar a crescente influência da orientação espiritualista do paciente sobre a tomada de decisões do profissional da saúde. Exemplo disso são as decisões sobre transfusão de sangue ou a manipulação do corpo imediatamente após a morte. O que acontece, então, se a vontade do moribundo e/ou de sua família não se enquadra entre os procedimentos costumeiros ou entre os ritos religiosos mais conhecidos dos profissionais da saúde que o atendem? Até que ponto cabe ao profissional não familiarizado com certos procedimentos (que podem Ihe parecer até bizarros) levar em consideração o lado espiritualista do paciente? Acreditamos que, para a solução desses e outros dilemas similares, o profissional achará subsídios na bioética.

\section{O papel da bioética nos processos religiosos da terminalidade}

Por mais que a medicina, a psicologia ou outros saberes e ciências tenham oferecido orientações para ajudar o profissional a tomar decisões que beneficiem o paciente, merecem destaque as orientações da bioética em relação à fase terminal da vida. A "distância" entre o profissional e o paciente pode ser diminuída ou vencida se forem levados em conta certos princípios, como respeito à autonomia do paciente, a beneficência e, de modo especial, a alteridade.

Para os bioeticistas sul-americanos, no princípio da alteridade estão englobados valores humanos como cuidado, compaixão e misericórdia. Isso porque, se definida de maneira sucinta - porém esclarecedora -, a alteridade traduz-se em um movimento por meio do qual o indivíduo procura se colocar no lugar do outro e sentir ou vivenciar suas necessidades, dores e limitações. Para Hennezel e Leloup ${ }^{9}$, não ter medo do sofrimento do outro e assumi-lo dentro de si seria a verdadeira compaixão. Embora o princípio da alteridade não seja discutido com frequência em livros de bioética, ele é de extrema importância. Ironicamente, essa assertiva costuma ser constatada em situações em que tal princípio está ausente, como, por exemplo, quando encontramos um profissional da saúde que se atém apenas à técnica em seus procedimentos.

As resoluções do profissional podem se modificar drasticamente se ele estiver direcionado pelo princípio da alteridade, colocando-se no lugar do 
paciente e olhando a questão "com os olhos do outro". A diferença entre essas decisões foi verificada por Asai, Fukuhara e Lo ${ }^{10}$, que compararam a conduta de médicos japoneses em um caso proposto de um paciente idoso em fase terminal e com câncer disseminado. Os médicos, inicialmente, optaram por condutas bastante agressivas e invasivas direcionadas à manutenção da vida do paciente. Numa segunda etapa, os pesquisadores solicitaram aos médicos que procurassem se colocar no lugar do paciente e indicassem quais condutas aplicariam a si mesmos. A taxa de intervencionismo e procedimentos invasivos caiu drasticamente, as transfusões sanguíneas baixaram de $74 \%$ para $29 \%$, a nutrição parenteral total passou de $67 \%$ para $33 \%$ e o uso de drogas vasopressoras caiu de $61 \%$ para $25 \%$. Demonstrava-se assim que, enquanto o paciente é visto como objeto, as decisões tendem a reproduzir a perspectiva técnica, que, em primeira instância, constitui o cerne da transmissão formal de conhecimento que formou o profissional, mas quando o médico se coloca no lugar do outro, personificando um ato de compaixão, são diferentes os procedimentos que ele adota.

Cada ser tem vários sistemas de valores e crenças, mesmo os éticos e os religiosos. Esses sistemas podem não exercer influência de destaque na juventude ou na maturidade, mas usualmente ganham poder no período terminal da vida. Nossa atitude perante a morte é sempre herança de nossa cultura e religião, a cujas representações costumamos corresponder. A imagem que temos da morte e do sofrimento está internalizada em nós, mas quase nunca a analisamos. Por isso, a questão da morte pode ser vista sob perspectivas diversas e de acordo com o ambiente cultural. E o profissional nem sempre conhece essas diferentes visões.

\section{Aplicando os princípios da autonomia e da alteridade}

O cuidado, a compaixão e a misericórdia, valores alojados no cerne do princípio bioético da alteridade, vão exigir reflexão e estudo do profissional da saúde que trata de doente em fase terminal, tal qual o princípio do respeito à autonomia do paciente. Quando as necessidades do paciente são oriundas de crença espiritual, será mais fácil para o profissional interpretá-las, entendê-las e, possivelmente, acomodá-las ao ambiente hospitalar se tiver algum conhecimento sobre tal crença. Os dados aqui oferecidos podem representar uma oportunidade de reflexão sobre o respeito às crenças alheias, o que constituiria um processo bioético (e, assim, “humano") de acolhimento, para contrabalançar o processo de tecnicização que cerca o paciente. Daí a necessidade de se discutir aqui não só a relação do profissional com o paciente na terminalidade da vida, mas salientar ainda aspectos do processo de morrer, como, por exemplo, a manipulação do corpo e a maneira como esse corpo será descartado.

\section{Perspectivas sobre a morte e o morrer}

\section{Budismo}

O budismo não é estruturado como um bloco homogêneo de doutrinas, como acontece em várias outras religiões. Possui diversas escolas e princípios filosóficos, por vezes até divergentes. Aqui são focalizados aspectos comuns a seus ramos no que diz respeito à morte e ao morrer.

Estão entre os conceitos básicos do budismo que (1) tudo no universo é impermanente e todos os seres que nascem estão fadados a morrer e que (2) o sofrimento é uma constante no universo, e todos os seres sofrem, envelhecem, adoecem e morrem. Esses preceitos fazem parte das chamadas Quatro Nobres Verdades ${ }^{11}$.

Integrando os ensinamentos budistas está o treinamento constante da mente para que se mantenha calma e observadora, especialmente nos momentos próximos à morte. Essa preparação para a morte está presente em quase todas as práticas budistas, entre as quais se destaca a prática para a morte consciente, chamada de $P^{\prime}$ owa ${ }^{12}$. 0 texto mais famoso do budismo sobre a morte é o "Livro Tibetano dos Mortos" (Bardo Thodol), que descreve em detalhes a passagem deste mundo para o outro.

Existe no budismo a noção de reencarnação posterior à morte física do corpo. Assim, no pensamento budista são inúteis e contraproducentes os choros e as lamentações dos familiares e amigos nos momentos que antecedem ou logo após a morte da pessoa. São considerados muito importantes grandes períodos de silêncio para o doente poder fazer suas meditações e seus rituais sem ser incomodado.

Antes de o doente emitir seu último suspiro, o acompanhante deve dar, suavemente e com a ponta do indicador direito, uma sucessão de pequenos toques exatamente no centro do topo da cabeça do recém-falecido, para atrair seu foco de atenção para o chamado chacra coronário, que ali se localiza e por onde se acredita que o espírito deixe o corpo ${ }^{13}$. Podem ser usadas também algumas substâncias especí- 
ficas, que são colocadas no topo da cabeça, a fim de atrair a consciência para o chacra coronário ${ }^{14}$, mas não se deve tocar em nenhum outro local do corpo nesse momento, o que seria um desrespeito às crenças do moribundo (e, portanto a sua autonomia). Também haveria uma quebra do princípio bioético da não maleficência, pois, pela visão do budista, se estaria causando mal ao paciente e prejudicando-o na sua preparação para uma posterior reencarnação.

Os budistas acreditam que o espírito da pessoa possa demorar a sair do corpo, o qual deverá, sempre que possível, estar em decúbito lateral direito ${ }^{15}$. 0 período médio de saída é de três dias, mas eles creem que o processo pode demorar até sete dias. Assim, os budistas têm grande preocupação com as manipulações feitas no corpo após a morte, que devem ser evitadas ao máximo. Havendo absoluta necessidade de manipular o corpo, deve-se tocar antes em sua cabeça ${ }^{15}$. A constatação da saída do espírito é confirmada por alguns sinais físicos que o corpo apresenta e que são declarados por um monge mais experiente, líder do grupo que acompanha o morto ${ }^{13}$. A partir do momento em que o espírito foi liberado, o cadáver já não é importante para o budismo, diferentemente do que ocorre em outras religiões.

Uma prática usual do budismo na hora da morte é a recitação de cânticos e mantras ou a leitura de textos específicos. É a chamada liberação pela escuta, pois se acredita que o espírito possa se guiar pelas palavras proferidas pelos acompanhantes ${ }^{14}$. É recomendação pessoal do atual Dalai Lama, da ramificação Vajrayana do budismo, que amigos se revezem falando baixinho ao ouvido do paciente e passando-Ihe ensinamentos espiritualistas, até o cessar da respiração ${ }^{16}$.

Outra preocupação é trazer para o quarto do paciente seu altar de orações, o qual deverá ficar constantemente à vista, constituindo-se em ato de respeito a sua autonomia de crença. Porém, muitas vezes, tal procedimento pode provocar incômodo para a parte administrativa do hospital, que mantém controle sobre a entrada e a permanência de objetos na área hospitalar. Desejável seria, então, que os administradores levassem em consideração o princípio bioético da beneficência, já que a aceitação de certos objetos ligados ao culto do paciente resultará em maior tranquilidade para a pessoa em seus momentos finais ${ }^{17}$.

Não há, nas práticas budistas, o apoio ao suicídio assistido. Também não é aceito o uso de medicamentos que prolonguem a vida e que, ao mesmo tempo, coloquem o paciente inconsciente, pois é muito importante para o budista fazer a transição para outro plano o mais consciente e calmamente possível ${ }^{18}$. Há também a execução do Tonglen, uma prática respiratória que pode ser realizada pelo acompanhante do moribundo, conhecida como "transfusão de serenidade" ou "transmissão de serenidade". O acompanhante faz a prática para acalmar a si próprio e transmitir ao moribundo a serenidade por ele alcançada ${ }^{19}$. Quanto ao funeral, quase sempre é escolhida a cremação ${ }^{17}$.

\section{Espiritismo}

É uma religião (ou, como preferem alguns, uma doutrina) que foi codificada por Alan Kardec no século XIX. Seus textos mais famosos são "O livro dos espíritos" e "O evangelho segundo o espiritismo". Este último é baseado nos evangelhos cristãos, mas recebe interpretações dos chamados médiuns mentores. $\mathrm{O}$ espiritismo tem muitos pontos em comum com o cristianismo, como a figura de Jesus Cristo com seus discípulos e, como já mencionado, os evangelhos bíblicos.

Um ponto fundamental de divergência entre as duas religiões diz respeito às questões da reencarnação e do contato com os chamados espíritos desencarnados. Em comum com o budismo, tem as noções de chacras como centros de força do corpo e a teoria reencarnacionista. Entretanto, ao admitir uma nova encarnação somente em outro corpo humano, difere do budismo, que admite a possibilidade de reencarnação em corpo de animal.

O espiritismo vê o ser humano em constante processo de aperfeiçoamento, por meio das lições de suas inúmeras vidas. Considera o ser responsável por tudo que lhe acontece, assim compartilhando com os budistas a noção de karma (lei de ação com sua consequente reação). Seguindo tal princípio, o espiritismo valoriza a vida até seu último suspiro, já que este é considerado uma forma de aprendizado, e não admite a eutanásia e, em alguns casos, nem mesmo a ortotanásia ${ }^{20}$.

Seu rito funerário é o enterro. Porém, se for o método preferido, pode-se fazer cremação, mas somente depois de três dias da constatação médica do óbito, porque se acredita que uma cremação anterior a esse prazo traria um processo doloroso ao espírito do morto, o qual ainda mantém laços energéticos com o corpo físico, e também por ser a cremação vista como um processo muito rápido de separação entre espírito e corpo. Cabe acrescentar que, para os espíritas, o processo crematório só deve ser usado por pessoas muito evoluídas nos sentidos ético e espiritual ${ }^{21}$. 
Há uma diferença entre as ideias de morte (a morte do corpo físico, a irreversibilidade do processo vital) e desencarnação (quando a parte sutil da pessoa consegue romper os laços de energia que a ligavam ao corpo físico e se libera totalmente). Mas, no espiritismo, a palavra "desencarnação" pode ser usada nos dois sentidos.

Não há, no espiritismo, crenças fortemente contrárias ao uso de órgãos do morto para transplante, embora se leve em consideração o tipo de morte (se violenta ou não) e o estado emocional e psicológico da pessoa na hora da morte, bem como prévias manifestações de vontade da pessoa quanto a ser ou não doadora dos seus órgãos ${ }^{22}$. Aqui pode surgir um confronto entre o princípio da beneficência (se os familiares desejarem que os órgãos do falecido sejam usados para fins de transplante) e o da não maleficência (se o dirigente do grupo espírita ao qual pertencia o morto achar que este não tem condição espiritual para fazer doação). Para Teixeira ${ }^{23}$, na crença espírita, um doador involuntário e não preparado pode sentir, no plano sutil, a falta do órgão e, assim, sofrer por ainda estar ligado emocionalmente a seu corpo físico, o que também poderia contribuir, energeticamente, para a instalação de um processo de rejeição no organismo do receptor.

Não existem disposições contrárias à manipulação do cadáver. Não há também preocupação maior quanto ao estado de consciência do moribundo (ao contrário do budismo) e às medicações que lhe trariam certo nível de inconsciência, pois os espíritas acreditam que, no outro plano, sempre existirão as figuras conhecidas como amparadores, que ajudarão o morto a fazer a transição, esperando-o do outro lado ${ }^{22}$. Embora admitam a vantagem da transição mais consciente, acham que isso dependeria do grau de adiantamento espiritual da pessoa e de seus merecimentos nesta vida e em vidas anteriores.

O espiritismo entende a morte como parte natural da vida, e o medo da morte, como um fenômeno de reação instintiva de autopreservação. Os tipos de morte e de doença estarão sempre ligados a uma herança cármica. Os espíritas observam, ainda, que o processo de desencarnação pode ser acompanhado de fenômenos mediúnicos e paranormais, decorrentes dos cortes energéticos entre o corpo físico e os chamados corpos sutis nessa hora ${ }^{21}$.

A doutrina espírita é bastante popular no Brasil, e várias pessoas que professam a religião católica professam, conjuntamente, o espiritismo.
Religiões de matriz africana (candomblé, umbanda e quimbanda)

São as chamadas religiões afro-brasileiras, pois guardam ligação com a chegada dos africanos escravizados ao Brasil. De acordo com Trindade ${ }^{24}$, são bem populares em vários estados brasileiros, principalmente entre a população negra. Em geral, essas religiões adotam cerimônias em que algumas pessoas - chamadas de "cavalos de santo" - entram em transe e "recebem" entidades espirituais, as quais "se ocuparão" de seus corpos, onde "cavalgarão" 25.

Essas religiões são muito ligadas à natureza $\mathrm{e}$ a seus fenômenos e, nesse sentido, podem até ser consideradas como religiões da natureza ou ecológicas. Seus seguidores acham importante a energia dos rios, do vento, do trovão e da mata, elementos vistos como pontos de consciência ou seres energéticos, estando todos ligados a seres humanos. Assim, o principal aprendizado é saber invocar e manipular as energias que se encontram na natureza, aí incluídos os animais.

Ensina Ferreira ${ }^{26}$ que, entre os ritos das religiões de matriz africana encontradas no Brasil, há aquele que permite o sacrifício ou oferenda de um animal para melhorar a saúde de um paciente, mesmo que na fase terminal. Esse sacrifício é considerado válido ainda que o doente não saiba que ele foi feito em sua intenção. Essa crença tem embasamento na noção de que o sangue seria uma potente fonte de energia, um verdadeiro agente de transformação, de cura ou de imantação. Quando criticados por quem diz estar defendendo os animais de um sacrifício, os praticantes costumam argumentar que, se todo mundo usa animais para tudo, por que não poderiam usá-lo em rituais de ajuda?

Em geral, somos zelosos de nossas cultura e crenças. Um visitante que entra calçado em certos templos da Índia pode ser expulso do local de maneira fisicamente agressiva e com gritos, enquanto no Brasil seria plenamente aceito em igrejas ou templos. Também na Índia, em algumas regiões, um turista poderia até ser linchado pela multidão se matasse uma vaca, enquanto, no Brasil, muitas pessoas fazem diversas celebrações ao redor de carne de animais assada. Esses exemplos pontuais demonstram como pode ser difícil superar os limites da própria visão de mundo.

Da mesma forma que nos exemplos acima, no Brasil são praticamente intransponíveis as dificuldades para o sacrifício de animais dentro da área hospitalar. Diante disso, a providência mais comum em relação aos doentes seguidores dessas religiões é sua retirada do hospital para que façam a transi- 
ção em suas próprias casas, com os rituais adequados. Assim, como no exemplo do sacrifício animal, é importante que o profissional procure sempre discernir, quando diante dos vários dilemas surgidos na terminalidade, se seu repúdio é gerado pela compaixão com o outro - o animal -, ou porque seu modo de pensar arraigado e sua cultura estão sendo questionados.

Os adeptos das correntes religiosas de matriz africana acreditam que o espírito do morto fica rondando o corpo, mas aceitam as decisões médicas de morte cerebral, não têm restrições ao transplante de órgãos e, diferentemente dos budistas, não acreditam que a manipulação do cadáver possa atrapalhar ou influenciar o espírito no período post mortem. Alguns grupos também aceitam a ideia da ortotanásia se um dirigente espiritual (conhecido como pai de santo ou babalorixá, que é o chefe do terreiro ou da casa onde se pratica a religião) afirmar que o espírito já não está mais no corpo, mesmo que o corpo esteja sendo mantido vivo por meio de aparelhos.

Os adeptos dessas religiões entendem que a morte faz parte do ciclo da natureza e que os parentes do morto não se devem deixar levar por fortes emoções, porque estas podem torná-los vulneráveis e fragilizados. Se isso acontece, pensam os umbandistas, os espíritos desencarnados ficam junto dos vivos durante atos como comer, beber ou fazer sexo, alimentando-se das energias emanadas por esses fenômenos fisiológicos ${ }^{27}$.

Acreditam na reencarnação, porém acham que ela se dá sempre no mesmo clã, ou seja, o espírito reencarna numa mesma linhagem familiar e entre membros que tiveram uma ligação especial em uma vida anterior. Nesse aspecto, difere do espiritismo, segundo o qual a reencarnação ocorre para a quitação de débitos (karma) e pode acontecer em qualquer família, em qualquer região do planeta.

Nas religiões de matriz africana existe também a crença de que todos os seres humanos possuem mediunidade em maior ou menor grau ${ }^{24}$. Diferentemente do espiritismo e do budismo, elas não têm textos dogmáticos, sua tradição é oral e seus ritos são bastante variados, embora sempre mantenham nexo com as energias da natureza.

\section{Catolicismo}

Em relação ao cadáver, a Igreja Católica não faz objeção ao fato de ele ser tocado ou manipulado e aceita a doação de órgãos e a condição de morte encefálica do paciente. Não concorda, porém, com o abreviamento do tempo de vida, não aprovando, portanto, a eutanásia, ainda que alguns líderes aceitem a ortotanásia. Não se acredita em reencarnação no catolicismo, embora exista a crença na ressurreição, que é a volta de todos os mortos, em carne e osso, no dia do Juízo Final.

Para o período de terminalidade da vida, a Igreja aconselha orações para alívio dos sofrimentos físicos e psíquicos, bem como o uso das chamadas bênçãos da saúde. Na hora da morte ou logo após, existe o ritual do sacramento da unção dos enfermos, ministrado pelos padres. Em grupos católicos mais conservadores, é mantida a tradição de serem feitas orações, pelos familiares e amigos presentes, no momento da morte, mas essa tradição está aos poucos desaparecendo. Existem, em algumas localidades do Brasil, outros rituais para a hora da morte, como, por exemplo: colocar uma vela na mão do moribundo ou morto; colocar quatro velas acesas, uma em cada canto do leito ou do quarto; dar um crucifixo para o moribundo segurar ao peito com as duas mãos; e lavar o corpo do morto logo após o desenlace. Quanto ao adulto em fase terminal que não professe o catolicismo, sempre que possível, a Igreja procura permissão para batizá-lo.

Os católicos têm duas preocupações de destaque quanto à morte: a primeira é com a morte súbita, porque acreditam em um juízo particular que acontece logo após a morte e para o qual a pessoa pode estar despreparada se morrer repentinamente; e a segunda é com aqueles que se suicidam. Houve já uma diminuição das restrições e preconceitos sobre os suicidas, mas, em algumas localidades, as discriminações continuam orientando a maneira de agir em relação a eles. Uma conduta que subsiste, mais comumente em comunidades muito pequenas, é a de enterrar o morto na parte de fora do cemitério, onde a Igreja ainda os "gerencia". Com isso, a família, já discriminada pelo ato do morto, fica ainda mais marginalizada, o que constitui violação do princípio bioético da justiça.

\section{O testamento vital}

Hoje não se pode mais falar sobre dilemas do profissional da saúde durante a fase de terminalidade do paciente sem mencionar o testamento vital. Ele compõe-se das diretivas antecipadas de vontade, entendidas como instruções que uma pessoa dá antecipadamente, relativas aos tratamentos que deseja ou que recusa receber no fim da vida, para o caso de se tornar incapaz de exprimir a sua vontade ou de tomar decisões por e para si própria ${ }^{28}$. 
Esse testamento, portanto, alinha-se em importância aos desejos manifestados pelo doente capaz de se fazer entender no decorrer da fase terminal. Assim como acontece em relação às vontades verbalizadas pelo doente, o profissional da saúde pode notar que, na base das vontades registradas pelo paciente antecipadamente, em geral detectamse raízes religiosas/espirituais. Por isso, o relacionamento do profissional com o paciente nas questões abrangidas pelo testamento vital também pode ser facilitado pelo conhecimento que o primeiro tem de concepções espiritualistas do segundo. Igualmente, podem ser amenizados os dilemas referentes ao cumprimento da vontade do doente e, portanto, referentes ao respeito à autonomia do outro.

Entendendo as razões espirituais que permeiam a manifestação de vontade de um paciente, o profissional da saúde consegue compreender, em nível mais profundo, a importância de seus desejos. Consequentemente, a atitude do profissional e as decisões que toma em relação ao testamento vital possuem melhor embasamento. Ao mesmo tempo, o profissional encontra maior facilidade em se deixar guiar, em suas ações, por princípios bioéticos, como o respeito à autonomia, a beneficência e a alteridade.

Aceitando-se como verdade que, para agir com maior serenidade, o profissional precisa de conhecimento sobre a espiritualidade de seu paciente, também se pode afirmar que a família do paciente é muitas vezes sua fonte de informações mais acessível. A decisão sobre quando colocar em vigor os desejos expressos no testamento vital (como, por exemplo, o momento de desligar as máquinas de suporte vital) também deve incluir a participação da família caso o paciente esteja incapaz de se manifestar. É para ela, portanto, que o profissional da saúde passa as informações sobre as condições extremas do paciente.

Nunes transcreve as normas que compõem a Proposta sobre suspensão e abstenção de tratamento em doentes terminais, dentre as quais destacamos: quando o doente se encontra incompetente e, portanto incapaz de decidir livremente, a informação clinicamente relevante deve ser partilhada com a família, entendendo-se por família aqueles que se encontram em maior proximidade com o paciente, independentemente da relação parental existente ${ }^{2}$.

Em texto de Nunes e Melo ${ }^{28}$ expõem-se suficientes aspectos da questão do testamento vital para que o leitor - paciente ou profissional da saúde
- possa tomar suas decisões, optando ou não pela adoção da Diretiva Antecipada de Vontade.

No Brasil, essa questão iniciou-se com a Resolução 1.995/2012, do Conselho Federal de Medicina ${ }^{29}$, que especifica as condições em que pode ocorrer a ortotanásia. Na vivência dos dilemas da terminalidade, tem-se constatado a crucial importância de se implementar no Brasil a prática do testamento vital escrito de próprio punho pelo paciente e registrado em cartório, no qual expressa sua vontade tanto em relação ao término da vida quanto em relação a sua vontade de ser doador de órgãos.

Entendemos que, no caso do Brasil, o testamento vital teria uma peculiaridade a mais a ser considerada e que a atenção a esse detalhe guardaria ligação direta com o princípio da alteridade. Conforme discutido neste texto, as manifestações de cunho religioso ou espiritualista têm-se diversificado muito no país. Assim, é possível que as instruções previamente dadas pela pessoa sobre o tratamento que deseja na fase terminal tenham de ser lidas a partir de um "código" gerado pela linha espiritual que ela segue.

Tomemos um exemplo muito simples e bastante comum. Uma pessoa instruiu, em seu testamento vital, que quer que os médicos "desliguem as máquinas" na eventualidade de ocorrer uma condição específica. Entretanto, sendo tal pessoa fiel aos ditames da Igreja Católica Apostólica Romana, naquele seu desejo poderia estar implícito outro desejo que, para ela, é pré-requisito de fundamental importância: receber o sacramento da unção dos enfermos antes das providências médicas finais. Não há garantia de que a família lembrará isso ao médico.

Além disso, cada hospital brasileiro pode estar preso a uma linha religiosa diferente. Então, o cuidado de fazer uma rápida indagação à família pode estar nas mãos do profissional da saúde. Cuidar para que seu paciente complete seu ciclo espiritual na terra de acordo com os rituais de sua crença traduz a prática dos princípios do respeito à autonomia, da beneficência e da alteridade num contexto da mais profunda compaixão. No exemplo do sacramento da unção dos enfermos, o profissional estaria respeitando seu paciente mesmo sabendo que este nem perceberia conscientemente que o sacramento Ihe foi ministrado. Em última instância, e conforme aprendemos de Alves e Selli ${ }^{30}$, respeitar a religiosidade do paciente pode ser considerado também um respeito a seus direitos culturais, os quais integram seus direitos humanos. 


\section{Considerações finais}

Independentemente de qual seja o código de ética do paciente, ou de quantas sejam as opiniões sobre a questão da terminalidade de vida, a atitude de não abandonar o paciente é essencial no período final de sua vida. Segundo Quill, Lo e Brock ${ }^{31}$, o ato de não abandonar é a obrigação ética central do profissional da saúde, refletindo seu compromisso com o paciente e seu código de ética. E, para isso, é necessário que o profissional da saúde seja capaz de entender - e, então, compreender - um pouco de suas necessidades no campo espiritual.

O conhecimento, ainda que sucinto, de como o fenômeno da morte é encarado por determinadas religiões, doutrinas e crenças possibilita algumas reflexões que consideramos importantes para os que lidam com essa situação, em especial o bioeticista. Deve sempre existir o respeito à autonomia de seguir diferentes crenças, por mais que sejam estranhas e fujam a nossos padrões. Esse exercício é fundamental para a qualidade do período de terminalidade de vida do paciente e, na fase em que este ainda está consciente, para seu melhor relacionamento com os profissionais que dele cuidam.

É preciso refletir que, em última análise, os pacientes têm crenças da mesma maneira que nós temos, ou poderíamos ter, e que ele gostaria de vê-las respeitadas tanto quanto gostaríamos de ver as nossas respeitadas. Sendo crenças, constituem apenas "possíveis verdades" muito particulares de cada gru- po, e não "verdades universais" ou fatos que possam ou devam ser provados. Assim, o cuidado do profissional para que o paciente encontre espaço para suas manifestações espirituais é uma atitude bioética que trará benefícios, enquanto sua supressão resultará em conflitos. Essa perspectiva é também adotada Alves e Selli, autores que apontam, entre os benefícios da bioética, a ressignificação da dimensão espiritual como uma necessidade cultural e, portanto, como parte inerente à dignidade humana ${ }^{30}$.

Acreditamos que, ao adotar uma atitude de compreensão em relação às crenças do paciente, o profissional revela seu interesse humano e espiritual por aquele que recebe seus cuidados. E essa preocupação com o outro é a própria tradução em atos dos princípios bioéticos da alteridade e do respeito à autonomia do doente. $\mathrm{O}$ momento da morte será um pouco menos complexo para ambas as partes - paciente e profissional da saúde - a partir dessa postura de tolerância, respeito e compaixão, elementos de suporte humano que não deveriam faltar nem poderiam ser substituídos pelo suporte tecnológico, como já foi preconizado por Potter ${ }^{5}$. 0 profissional da saúde trabalha, sim, pela vida, mas talvez esse suporte humano ajude a ele e ao paciente a entenderem que, como ensina Hegel ${ }^{32}$, vida e morte estão profundamente entrelaçadas, pois não há vida sem morte - em uma planta, a morte do botão permite a vida da flor, a morte da flor permite a vida do fruto, o qual nos vai permitir perceber o verdadeiro sentido da árvore.

\section{Referências}

1. Camarano AA. Envelhecimento da população brasileira: uma contribuição demográfica. $3^{\mathrm{a}}$ ed. In: Freitas EV, Py L, editores. Tratado de geriatria e gerontologia. Rio de Janeiro: Guanabara Koogan; 2011. p. 58-71.

2. Nunes R. Proposta sobre suspensão e abstenção de tratamento em doentes terminais. Bioética. 2009;17(1):29-39.

3. Associação Portuguesa de Cuidados Paliativos. Comentários referentes à proposta de "guidelines" sobre suspensão e abstenção de tratamento em doentes terminais. [Internet]. [acesso 14 set 2014]. Disponível: http://www.apbioetica.org/fotos/gca/12802541901211800343guidelines _p_11_apb_08.pdf

4. Salles AA. Transformações na relação médico-paciente na era da informatização. Rev. bioét. (Impr.). 2010;18(1):49-60.

5. Potter VR. Bioethics: bridge to the future. Englewood Cliffs: Prentice Hall; 1971.

6. Hellegers AE. La Bioéthique. Paris: Les Presses de l'Université; 1979. (Cahiers de Bioétique; vol 1).

7. Barnard D, Quill T, Hafferty FW, Arnold R, Plumb J, Bulger R et al. Preparing the ground: contributions of the preclinical years to medical education for care near the end of life. Acad Med. 1999;74:499-505.

8. Instituto Brasileiro de Geografia e Estatística. Censo 2010: número de católicos cai e aumenta o de evangélicos, espíritas e sem religião. [Internet]. [acesso 14 set 2014]. Disponível: http:// www.ibge.gov.br/home/pesquisa/pesquisa_google.shtm?cx=009791019813784313549\%3Aon z63jzsr68\& cof=FORID\%3A9\&ie=ISO-8859-1\&q=cat\%F3licos\&sa=Pesquisar\&siteurl=www.ibge. gov.br\%2F\&ref $=\& s s=1384 \mathrm{j} 227194 \mathrm{j} 10$ 
9. Hennezel M, Leloup JY. A arte de morrer: tradições religiosas e espiritualidade humanista diante da morte na atualidade. Petrópolis: Vozes; 2005.

10. Asai A, Fukuhara S, Lo B. Attitude of Japanese and Japanese-American physicians towards lifesustaining treatment. Lancet. 1995;346:356-9.

11. Mizuno K. Essentials of Buddhism: basic terminology and concepts of Buddhist philosophy and practice. Tóquio: Kosei Publishing; 1996.

12. Chagdud K. Comentários sobre P'owa. Três Coroas: Rigdzin; 2000.

13. Rinpoche S. O livro tibetano do viver e do morrer. São Paulo: Talento; 1999.

14. Rinpoche B. Morte e arte de morrer no budismo tibetano. Brasília: ShiSil; 1997.

15. Grupo de Trabalho Religiões e Saúde, editor. Manual da assistência espiritual e religiosa hospitalar. Porto: Comissão Ecumênica do Porto; 2010.

16. Dalai Lama. Advice on dying: and living a better life. Londres: Rider; 2004.

17. Smith-Stoner M. End of life preferences for practitioners of Tibetan Buddhism. J Hospice and Palliative Nurs. 2005 jul-ago:228-33.

18. Thondup T. Peaceful death joyful rebirth: a Tibetan-Buddhist guidebook. Boston: Shambala Publications; 2006.

19. Hennezel M. A arte de morrer. Petrópolis: Vozes; 1999.

20. Xavier FC. Ação e reação. Rio de Janeiro: Federação Espírita Brasileira; 2004.

21. Kardec A. O livro dos espíritos. Rio de Janeiro: Federação Espírita Brasileira; 2004.

22. Xavier FC. O consolador. Rio de Janeiro: Federação Espírita Brasileira; 2003.

23. Teixeira CM. Anatomia do desencarne. Porto Alegre: Quarup; 1977.

24. Trindade DF. Umbanda e sua história. São Paulo: Ícone; 2003.

25. Meneghetti D. O Rio Grande do Sul revelado em cultos africanos. Fotografe Melhor. 2011 jul:45.

26. Ferreira CP. Kardecismo e umbanda. São Paulo: Pioneira; 1961.

27. Silva WG. Candomblé e umbanda. São Paulo: Summus; 2005.

28. Nunes R, Melo HP. Testamento vital. Coimbra: Almedina; 2011. p.96.

29. Brasil. Resolução CFM no 1.995, de 9 de agosto de 2012. Diretivas antecipadas de vontade dos pacientes. Diário Oficial da União. Brasília, p. 269-70, 31 ago 2012. Seção I:269-70.

30. Alves JS, Selli L. Cuidado espiritual ao paciente terminal: uma abordagem a partir da bioética. Revista Bras. Bioética. 2007;3(1):65-85.

31. Quill TE, Lo B, Brock DW. Palliative options of last resort: a comparison of voluntarily stopping eating and drinking, terminal sedation, physician-assisted suicide, and voluntary active euthanasia. Jama. 1997;278:2.099-104.

32. Hegel GF. Fenomenologia do espírito. São Paulo: Nova Cultural; 1999. (Os Pensadores; vol. 16).

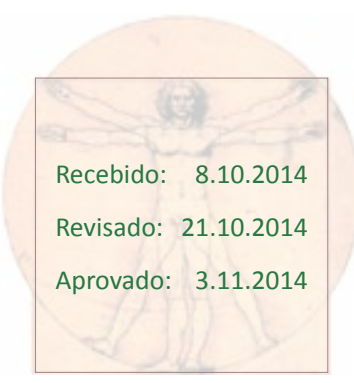

